\title{
Crystallization kinetics and morphology of melt spun poly(ethylene terephthalate) nanocomposite fibers
}

\author{
R. R. Hegde ${ }^{1}$, G. S. Bhat ${ }^{1 *}$, B. Deshpande ${ }^{2}$ \\ ${ }^{1}$ Department of Materials Science and Engineering, The University of Tennessee, Knoxville TN 37996, USA \\ ${ }^{2}$ Techmer PM, \#1 Quality Circle, Clinton TN 37716, USA
}

Received 16 March 2013; accepted in revised form 14 June 2013

\begin{abstract}
Natural nanoclay closite $\mathrm{Na}^{+}$incorporated melt spun poly(ethylene terephthalate) (PET) fibers were investigated for crystallization kinetics and morphology. Nature of clay dispersion and nanocomposite morphology were assessed using wide angle X-ray diffraction (WAXD) and transmission electron microscopy (TEM). Fiber mechanical properties were measured using single fiber tensile test. Combination of scanning electron microscopy (SEM) and energy dispersive spectroscopy (EDS) was used to investigate the fiber failure mode. Among nanocomposite PET fibers, sample with $1 \%$ clay performed better. WAXD and TEM micrographs of the fibers revealed intercalated and delaminated morphology. Size of agglomerate increased with percentage of add-on. SEM surface images showed significant variation in fiber diameter, voids and imperfections. Cross-sections of fractured surfaces revealed the presence of clay agglomerates at failure spots. Nanoclay reinforcement did not incur mechanical property benefits due to increase in voids and agglomerates in fiber section, especially at loading levels higher than one percent.
\end{abstract}

Keywords: nanocomposites, nanoclay, morphology, poly (ethylene terephthalate)

\section{Introduction}

Poly (ethylene terephthalate) (PET) is a low cost, engineering polymer that is used for making fibers, films, tapes, pressurized liquid containers and extruded parts. The microstructure and mechanical properties of PET can be significantly controlled by tailoring crystallization rate and degree of crystallinity with use of additives [1-5].

Nanoclay based on montmorillonite is a layered mineral deposit of smectite family extracted from volcanic ash. Unique features of nanoclay additives are; high modulus, its ability to be dispersed in platelet form within polymer matrix, and individual clay particle has very high aspect ratio with surface area of around 600 nanometers square and thickness of only one to a few nanometers. Earlier studies have reported improved properties in the final products derived by clay loading as low as $0.5 \mathrm{wt} \%$ compared to conventional composites with a large amount of fillers [6-11].

Earlier studies report improved mechanical and thermal stability properties [5, 12-14]. In order to see the property benefits, the nanoclay additive has to be uniformly dispersed within the matrix [15]. Based on the extent of dispersion of additives, there are three known morphologies of nanocomposites; exfoliated, intercalated and agglomerated, which are elucidated in our earlier paper [7]. Thermodynamically, the strongly hydrophilic clay and hydrophobic polymers lack attractive enthalpic forces to overcome the electrostatic force which pulls sheets together. The net effect is that the free energy of mixing between clay and polymer is positive, and so the mixing is not thermodynamically favorable.

\footnotetext{
${ }^{*}$ Corresponding author, e-mail: gbhat@utk.edu

(C) BME-PT
} 
In melt compounded systems with non-polar olefins, a favorable enthalpic interaction is achieved by addition of 'compatibilizer' like maleated polypropylene. Few studies also report organically modified nanoclay additives to increase the spacing between clay layers and achieve better dispersion [16].

There have been few attempts to describe the effect of nanoclay additives on crystallization, thermal and mechanical properties and morphology of PET fibers. Nucleating effect of clay additives in polyester systems has been studied before [17, 18]. Authors have reported two mutually opposite effects; nucleating ability of additive and growth retardation due to lack of diffusion [19]. Up to three times higher crystallization rate has been reported for PET nanocomposites compared to that of pure PET [1]. Compared to the large distinct spherulite in case of pure PET, PET-nanoclay nanocomposites formed small sized spherulites. Detailed crystallization kinetics and influence of clay additives on the spherulite formation is reported in earlier literature [20]. Presence of nanoclay not only promotes nucleation, but the huge surface area for platelet structure supports crystal growth $[1,21]$.

Earlier studies on mechanical properties give conflicting opinion about the improved mechanical property benefits. Xiao et al. [3] reported that the strong interaction between MMT layer and PET chains decreased the degree of orientation and crystallinity. Compared to non-polar olefins it's relatively easy to disperse nanoclay within the PET matrix due to strong interaction between nanoclay layer and PET molecules. Bizarria et al. [4] reported that mechanical properties of PET/organoclay nanocomposites were superior to that of the recycled PET in terms of strength and elasticity modulus. Chang et al. [2] produced and characterized PETorganoclay dodecyltriphenylphosphonium-mica hybrid fibers. They found that the strengths of the fibers increased up to a critical clay loading and then properties decreased above that critical clay concentration. Lu and Hay reported that the mechanism of deformation changed from ductile shear yielding to craze-crack growth due to presence of nanoclay [22].

Structure and morphology of polypropylene fiber nanocomposites, nonwoven nanocomposites: spun bond and melt blown nonwovens, has been reported before [7-9]. However, influence of additives on the structure and properties of PET fiber nanocom- posites, and crystallization kinetics PET nanocomposites is not reported anywhere in detail.

In this research, melt spun PET/Closite $\mathrm{Na}^{+}$composite fibers with additive wt $\%$ ranging from 1 to $5 \mathrm{wt} \%$ were characterized for crystallization kinetics, structure, morphology and mechanical properties.

\section{Experimental}

\subsection{Materials and methods}

PET-nanoclay concentrates with nanoclay additive wt $\%$ ranging from 1 to $5 \mathrm{wt} . \%$ were supplied by Techmer PM (Clinton, Tennessee, USA). PET resin (DAK Americas, Wilmington, NC, USA) had density of $1.35 \mathrm{~g} / \mathrm{cm}^{3}$ and intrinsic viscosity of 0.68 . The natural nanoclay additives (density $2.86 \mathrm{~g} / \mathrm{cc}$, moisture content $4-9 \%$, particle size $<25 \mu \mathrm{m}$ ) were purchased by Techmer PM from Southern Clay Products of Gonzales, Texas. Cloisite $\mathrm{Na}^{+}$a natural montmorillonite produced from highly refined bentonite was used for this study. Bentonite is acceptable for use as a direct food substance affirmed as generally recognized as safe by the FDA under 21CFR 184.115 [23].

The filaments were melt spun at $270^{\circ} \mathrm{C}$, using a Hills melt spinning unit with 41 round hole die. The spinning conditions were adjusted (speed in range of $220 \mathrm{~meters} / \mathrm{min}$ (mpm) to $890 \mathrm{mpm}$, and draw ratio of 4:1) to get consistent filaments without breakage. The composition of fibers is included in Table 1.

\subsection{Testing and characterization}

\subsubsection{Wide angle $X$-ray diffraction (WAXD)}

WAXD scans of the chopped fiber samples were conducted in reflection mode using the Phillips $\mathrm{X}$ Pert Pro X-ray diffraction system with $\mathrm{CuK}_{\alpha}$ radiation $(45 \mathrm{kV}, 40 \mathrm{~mA})$ of wavelength $1.542 \AA$. Samples were scanned in $2 \theta$ range of 2 to $40^{\circ}$ and step size of $0.02^{\circ}$ for $1 \mathrm{sec}$ at each step.

\subsubsection{Transmission electron microscopy (TEM)}

Ultra thin sections (less than $70 \mathrm{~nm}$ thick) were obtained using a RMC Power tome CRX microtome equipped with diamond knife. Nanocomposite fibers were doped within the epoxy block and the epoxy block with the fibers was used for sectioning. Details of sample preparation is discussed in earlier publications $[8,9]$. Specimen temperature was $-100^{\circ} \mathrm{C}$ and Glass knife temperature was set to $-103^{\circ} \mathrm{C}$. 
Sections were mounted on standard 400 mesh $\mathrm{Cu}$ grids and TEM images were taken using the Hitachi H-800 Electron Microscope operated at $200 \mathrm{kV}$.

\subsubsection{Single fiber tensile test}

Single fiber tensile test was carried out using a Thwing-Albert EJA 1000 (West Berlin, NJ, USA) tensile tester equipped with a $2000 \mathrm{~g}$ load cell as per ASTM 3822 [24]. Single fibers taken from various portions of the yarn were pasted on cardboard templates as shown in Figure 1. To avoid jaw-slipping, fibers were glued using epoxy resin and allowed to cure before testing. After mounting the template within the jaws of the tensile tester, template is cut off to test the single fiber only at a gauge length of $2.5 \mathrm{~cm}$ at a speed of $2.5 \mathrm{~cm} / \mathrm{min}$. Average of 10 readings is reported for tenacity and breaking elongation. Tenacity is defined as the breaking force in grams per denier. Tensile modulus was calculated from the initial region of load-elongation plots up to $2 \%$ elongation.

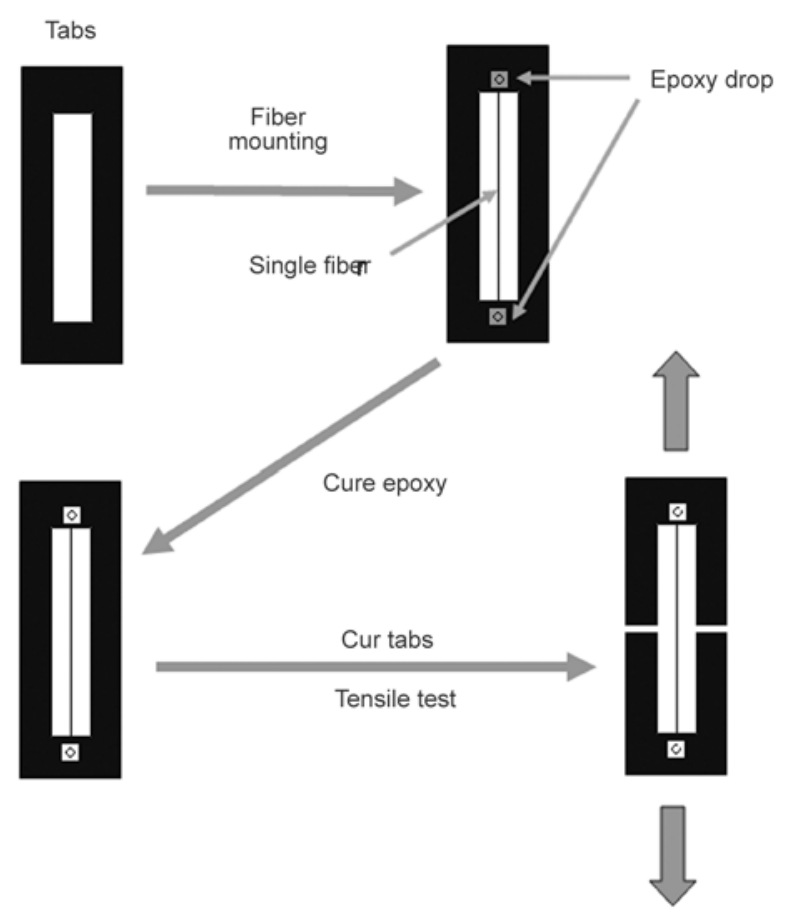

Figure 1. Schematic of sample preparation steps used for the single fiber tensile test

\subsubsection{Scanning electron microscopy}

Scanning Electron Microscopy (SEM) images of the fiber surface, and tensile failed fiber cross-sections were taken using the Leo 1215 Field emission gun. The samples were gold coated for 10 seconds using the SPI sputter coater to minimize charging. Image magnification was in the range of 100 to $1700 \times$.

\subsubsection{Energy dispersive spectrometers (EDS)}

The Oxford Pentafet EDS system was used to evaluate chemical composition in failure spots of nanocomposite. ZAF Quantitative method: ZAF (3 iterations) with the system resolution of $127 \mathrm{eV}$ and running Link ISIS software were used for data analysis. Presence of agglomerates at the fiber cross-sections was analyzed using EDS.

\subsubsection{Differential scanning calorimetry (DSC)}

Thermal analysis was carried out using the Mettler Toledo (Mettler, Columbus, OH, USA) DSC 822e. Samples were heated in the temperature range of 40 to $300^{\circ} \mathrm{C}$ at a heating rate of $10^{\circ} \mathrm{C}$ per minute in the $\mathrm{N}_{2}$ atmosphere, held at $300^{\circ} \mathrm{C}$ for $10 \mathrm{~min}$ and cooled to room temperature at a cooling rate of $20^{\circ} \mathrm{C}$ per minute. Percentage of crystallinity $X_{\mathrm{c}} \%$, of samples were calculated from enthalpies of crystallization using Equation (1):

$X_{\mathrm{c}} \%=\frac{\Delta H}{(1-\varphi) \Delta H_{100 \%}} \cdot 100$

where $\Delta H$ is the measured heat of fusion of the sample and $\Delta H_{100 \%}$ the heat of fusion of the $100 \%$ crystalline PET, taken as $115 \mathrm{~J} / \mathrm{g}$ for this study and $\varphi$ is the weight fraction of nanoclay additive. For isothermal relative crystallization studies, fiber samples were heated from 40 to $300^{\circ} \mathrm{C}$ at a heating rate of $50^{\circ} \mathrm{C} / \mathrm{min}$, held at $300^{\circ} \mathrm{C}$ for $10 \mathrm{~min}$ to erase all previous thermal history, and cooled at the rate of $-80^{\circ} \mathrm{C} / \mathrm{min}$ from $300^{\circ} \mathrm{C}$ to crystallization temperature of 215,220 and $225^{\circ} \mathrm{C}$ and held for $20 \mathrm{~min}$ at each crystallization temperature. The isothermal crystallization kinetics was analyzed by evaluating degree of crystalline conversion as a function of time at a constant temperature. The relative crystallinity at different crystallization time $X(t)$, was obtained from the ratio of the area of the exotherm up to time $t$ divided by the total exotherm given by Equation (2), where $Q_{\mathrm{t}}$ and $Q_{\infty}$ are the heat generated at time $t$ and infinite time, respectively, and $\mathrm{d} h / \mathrm{d} t$ is the heat flow rate [25]. Assuming that the relative crystallinity increases as a function of time, timedependent relative crystallinity $X(t)$ was estimated by Avrami Equation (3). The Avrami equation in the simple form represents unimpeded spherical crystal 
growth [26]. Equation (3) can be rearranged in double logarithmic form as Equation (4):

$X(t)=\frac{Q_{\mathrm{t}}}{Q_{\infty}}=\frac{\int_{0}^{\mathrm{t}}\left(\frac{\mathrm{d} h}{\mathrm{~d} t}\right) \mathrm{d} t}{\int_{0}^{\infty}\left(\frac{\mathrm{d} h}{\mathrm{~d} t}\right) \mathrm{d} t}$

$1-X(t)=\exp \left(-K t^{\mathrm{n}}\right)$

$\log [-\ln (1-X(t))]=\log K+n \log t$

From the plot of $\log [-\ln (1-X(t))]$ versus $\log (t)$, value of $n$ (slope) and $K$ ( $y$-intercept) was determined. In this equation, $n$ is the Avrami exponent which corresponds to nucleation and growth parameter and $K$ is the rate constant that describes the crystallization rate and, $t$ is the crystallization time [27].

\section{Results and discussion}

WAXD scans of neat nanoclay additives control PET and nano-composite fibers of different clay composition are shown in Figure 2. Nanoclay additives show peak corresponding to (100) plane at $2 \theta$ of $6.96^{\circ}$, which correspond to $d_{(100)}$ spacing of $1.26 \mathrm{~nm}$. Nanocomposite fiber WAXD scans do not show any peak corresponding to (100) plane of nanoclay. This disappearance of clay signature in the nanocomposite fiber is due to high shear stress involved in the melt spinning extruder. Similar results were observed in case of polypropylene melt spun fibers [7], melt blown nanocomposites webs [8] and spun bond nanocomposites [9]. Peak at $2 \theta=$ $17.8^{\circ}$, corresponds to the $(010)$ diffraction plane of the triclinic crystal of PET [28]. Sample PETFC5 showed lower crystallinity in XRD analysis.

TEM micrographs of PETFC1, PETFC2 and PETFC5 are shown in Figures 3a-3i. Micrographs reveal intercalated and delaminated structure of platelets. Fiber cross section showed particle size in range of 200-300 nm for PETFC1, $300 \mathrm{~nm}$ to $1 \mu \mathrm{m}$ for PETFC2 and 1 to $3 \mu \mathrm{m}$ for PETFC5. Each of these clay platelets at high magnification show significant polymer chain intercalation. Platelets are delaminated and lack the ordered structure.

Micrographs also reveal difference in the clay stack distribution along the fiber cross-section (Figure 3a). Clay stacks near the fiber diameter are smaller fragments whereas the particles at center portion of the fiber are larger and randomly oriented. This differ-
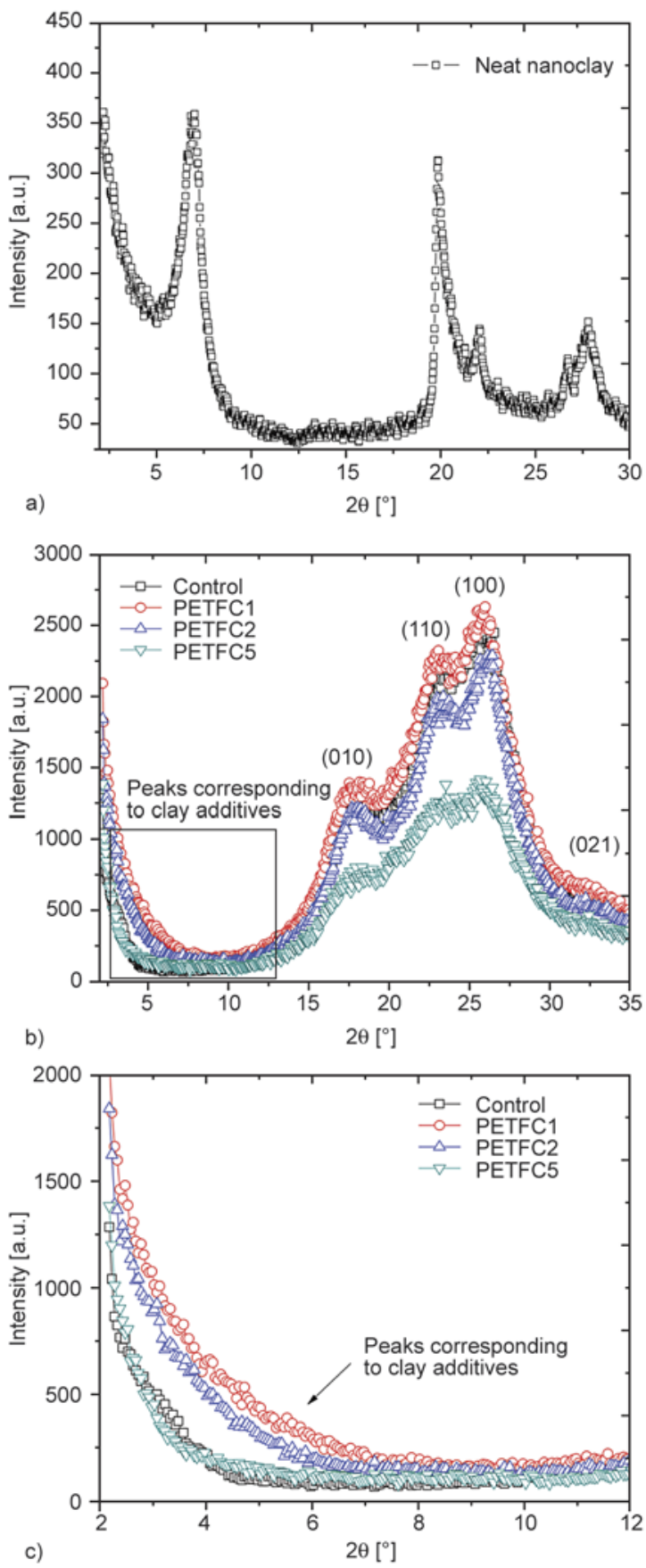

Figure 2. WAXD of (a) nanoclay additive, (b) PET nanocomposite fibers, (c) the peak corresponding to (100) plane of nanoclay in lower $2 \theta$ range

ence in the additive distribution is due to the 'wall effect', an effect which leads to reduction in concentration of suspension adjacent to the solid wall of flow channel. Also, the particles near fiber surface of PETFC1 and PETFC2 have higher polymer chain intercalation compared with ones at the center as shown in Figure 3d, 3e. This higher chain intercalation in conformity to other literature data $[8,9]$ is due to the higher shear rate experienced by polymer melt near the wall of the spinneret hole. 


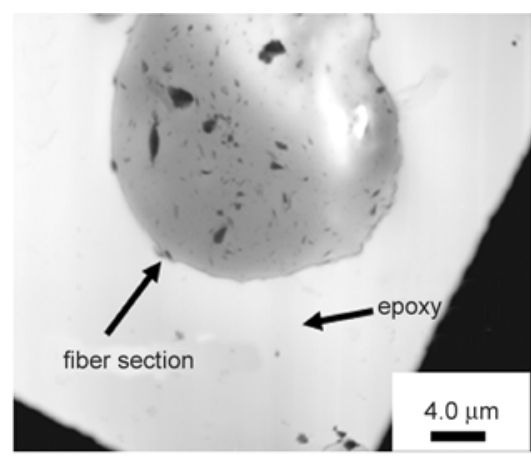

a)

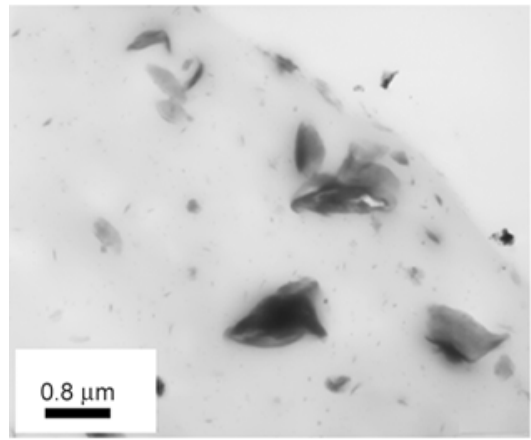

d)

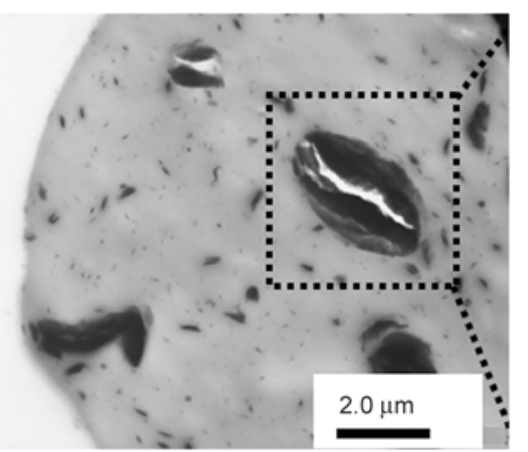

g)

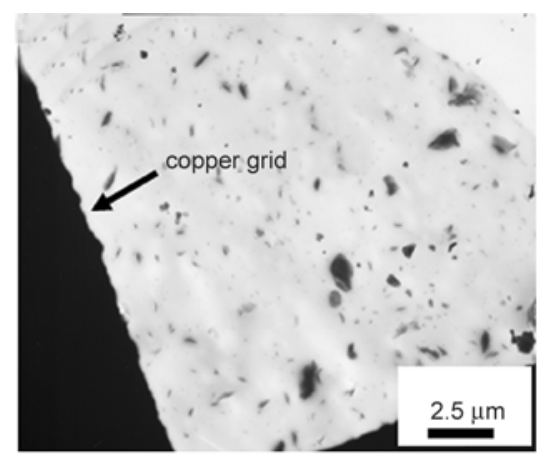

b)

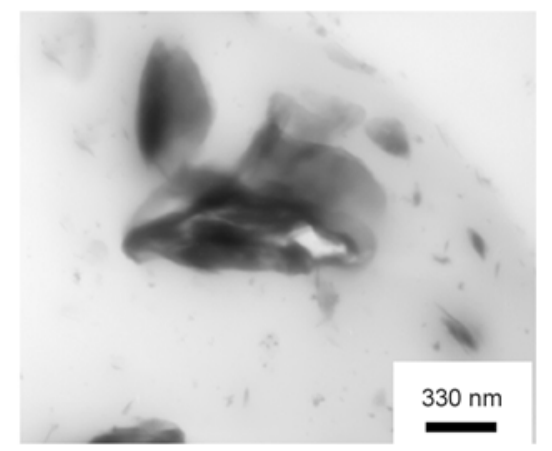

e)

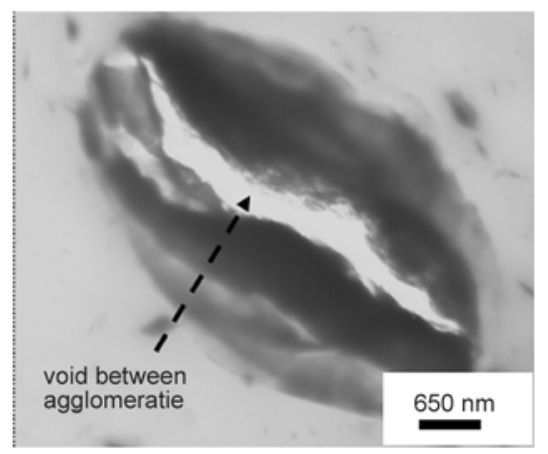

h)

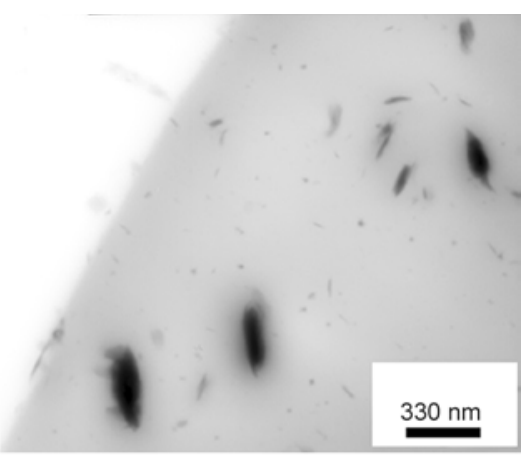

c)

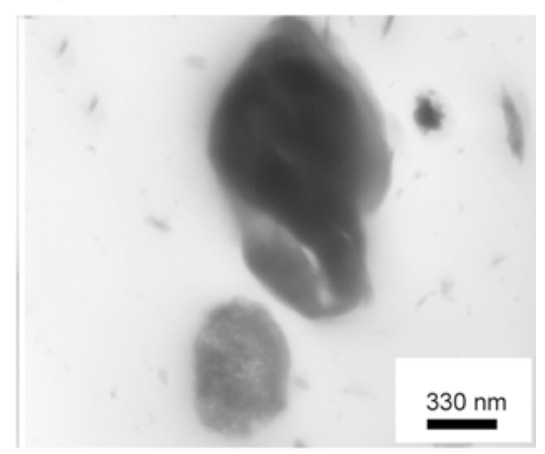

f)

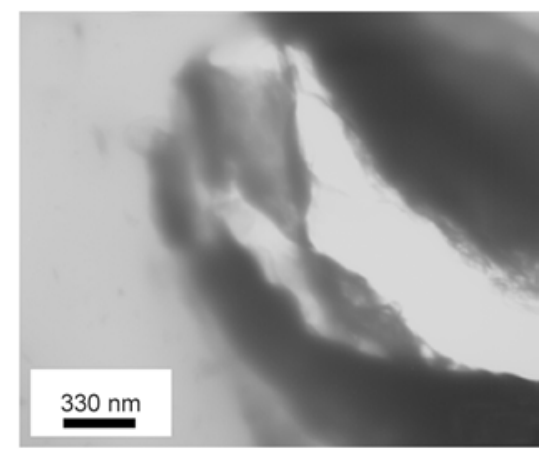

i)

Figure 3. TEM image of a), b), c) PETFC1 (fiber with $1 \mathrm{wt} \%$ clay additive), d), e), f) PETFC2 (fiber with 2 wt $\%$ clay additive), g), h), i) PETFC5 (fiber with 5 wt $\%$ clay additive)

At higher weight $\%$, clay causes increased amount of voids and weak spots within the fiber as observed from TEM images of fiber section (Figure $3 \mathrm{~g}, 3 \mathrm{~h}$ and 3i. Most of the micrographs of PETFC5 indicate that the tactoids had voids as shown in Figure $3 \mathrm{~g}$. We anticipate this void generation might have developed due to die swell or extrudate swell. Die swell is a phenomenon related to entropy and occurs due to relaxation of polymer melt as it comes out of spinneret orifice. It is well known that there is strong interaction between PET chains and clay platelets, whereas between clay platelets force is just weak Van der Waals force. Hence, during die swelling, tactoids in PETFC5 might have split open to develop voids as shown in Figures $3 \mathrm{~g}$ and $3 \mathrm{~h}$.

Results of thermal analysis obtained from differential scanning calorimetry (DSC) cooling segment are summarized in Table 1. Onset of crystallization and peak crystallization temperature are 4 to $8^{\circ} \mathrm{C}$ higher for samples with additives, which indicates

Table 1. DSC thermal analysis results of PET fibers in cooling segment

\begin{tabular}{|l|c|c|c|c|c|}
\hline \multicolumn{1}{|c|}{ Sample } & $\begin{array}{c}\text { Clay wt. } \\
{[\mathbf{\%}]}\end{array}$ & $\begin{array}{c}\text { Onset } \\
{\left[{ }^{\circ} \mathbf{C}\right]}\end{array}$ & $\begin{array}{c}\text { Peak } \\
{\left[{ }^{\circ} \mathbf{C}\right]}\end{array}$ & $\begin{array}{c}\text { Heat flow } \\
{[\mathbf{J} / \mathbf{g}]}\end{array}$ & $\begin{array}{c}\text { Crystallinity } \\
{[\mathbf{\%}]}\end{array}$ \\
\hline Control PET & 0 & 221 & 212 & 199 & 44 \\
\hline PETFC1 & 1 & 224 & 221 & 216 & 47 \\
\hline PETFC2 & 2 & 224 & 220 & 215 & 47 \\
\hline PETFC5 & 5 & 224 & 220 & 215 & 48 \\
\hline
\end{tabular}


nucleating ability of nanoclay. Crystallinity wt $\%$ of samples is slightly higher for samples with clay additives.

Results of crystallization kinetics are shown in Figure 4. For nanocomposites, crystallinity begins and reaches saturation about 40 seconds before control PET. The relative crystallinity results for samples are shown in Figure 4b. All samples exhibit sigmoid shaped time dependence, which indicates two different stages of crystallization. Initial faster slope change represents nucleation and subsequent slower slope change represents growth and impingement of growing spherulites. Avrami plot is shown in Figure 4c. Avrami exponent n, growth parameter $K$ and half time of crystallization $t_{(1 / 2)}$ values are listed in Table 2. Avrami exponent $\mathrm{n}$ varies from 1 to 3 . The $\mathrm{n}$ value of 3 corresponds to three dimensional sphere like growth form and lower $\mathrm{n}$ value indicates heterogeneous two dimensional rod-like growth forms [26-30]. Compared to control PET, crystallization half time $t_{(1 / 2)}$ is lower for nanocomposites. Also with increase in temperature, $K$ value decreases and $t_{(1 / 2)}$ increases which indicates decrease in crystallization rate.

Single fiber tensile strength results are summarized in Figure 5 and Table 3. Nanocomposite fiber strength is less than that of the control PET fiber, which is probably due to non-uniform dispersion and agglomerations even at lower weight percentage add on as shown in TEM micrographs (Figure 3). Among nanocomposite fibers, sample with $1 \%$ clay showed higher tenacity but lower elongation compared to sample with $2 \mathrm{wt} \%$ clay which indicates excessive variability in all the samples. The variation in properties is due to agglomerates of nanoclay as observed by TEM. Tenacity depends

Table 2. The crystallization half time $-t_{(1 / 2)}$ at $215^{\circ} \mathrm{C}$.

\begin{tabular}{|c|c|c|c|c|}
\hline \multirow{3}{*}{ Sample } & $\begin{array}{c}\mathbf{T} \\
{\left[{ }^{\circ} \mathbf{C}\right]}\end{array}$ & $\mathbf{n}$ & $\mathbf{K}$ & $\begin{array}{c}\mathbf{t}_{(\mathbf{1 / 2})} \\
{[\mathbf{s}]}\end{array}$ \\
\hline \multirow{3}{*}{ Control } & 215 & 3.2 & 0.8 & 83 \\
\cline { 2 - 5 } & 220 & 3.3 & 0.3 & 112 \\
\cline { 2 - 5 } & 225 & 1.1 & 0.3 & 198 \\
\hline \multirow{3}{*}{ PETFC1 } & 215 & 2.3 & 1.3 & 53 \\
\cline { 2 - 5 } & 220 & 2.7 & 0.4 & 64 \\
\cline { 2 - 5 } & 225 & 0.7 & 0.4 & 100 \\
\hline \multirow{3}{*}{ PETFC2 } & 215 & 2.9 & 0.8 & 55 \\
\cline { 2 - 5 } & 220 & 3.4 & 0.5 & 62 \\
\hline \multirow{3}{*}{ PETFC5 } & 225 & 0.7 & 0.2 & 68 \\
\cline { 2 - 5 } & 215 & 2.5 & 1.0 & 55 \\
\cline { 2 - 5 } & 220 & 2.5 & 0.2 & 80 \\
\hline
\end{tabular}

on the peak stress, which in turn depends on the reinforcing effect and extent of load transfer between nano platelets and matrix, whereas the elongation depends on the extent of drawdown of fibers. Elongation or extent of drawdown depends on the continuity in the molecular network. Even though sam-
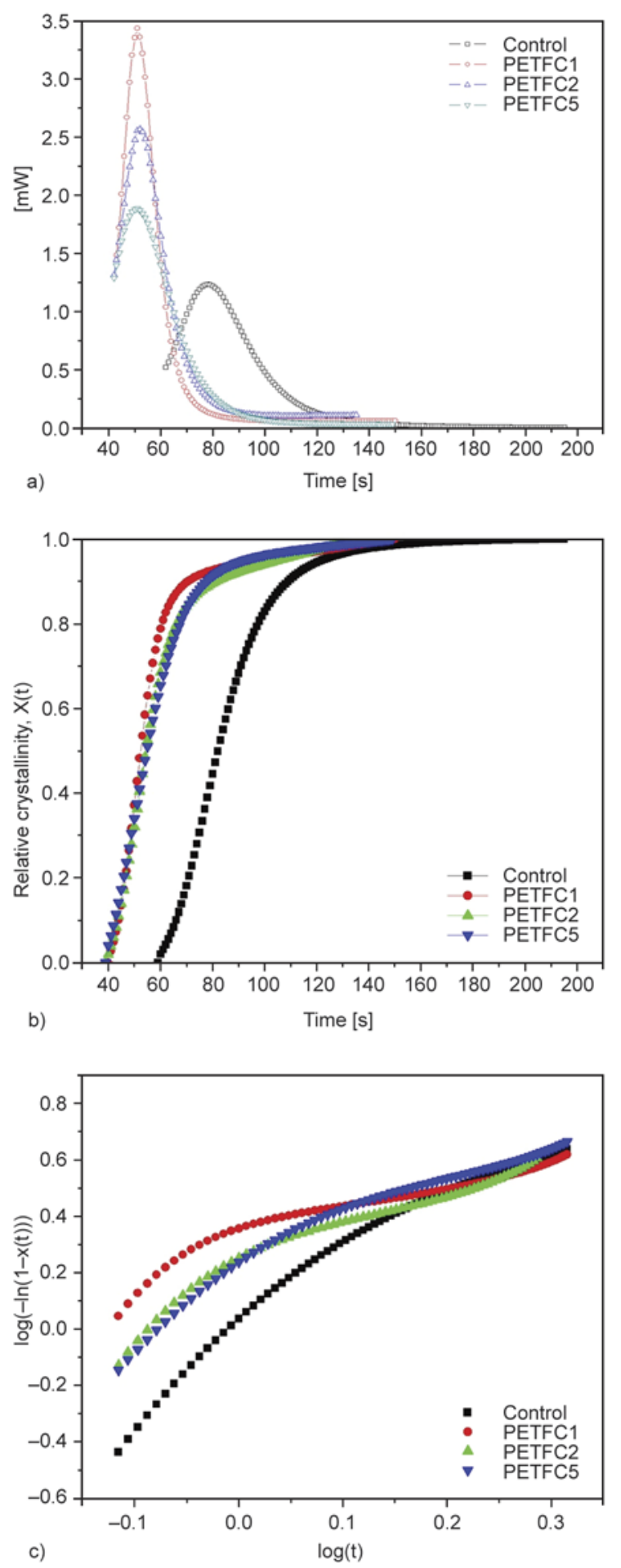

Figure 4. Results from crystallization kinetics study at $215^{\circ} \mathrm{C}$ (a) degree of crystalline conversion as a function of time, (b) relative crystallinity $X(t)$ for different PET fibers, and (c) Avrami plots 


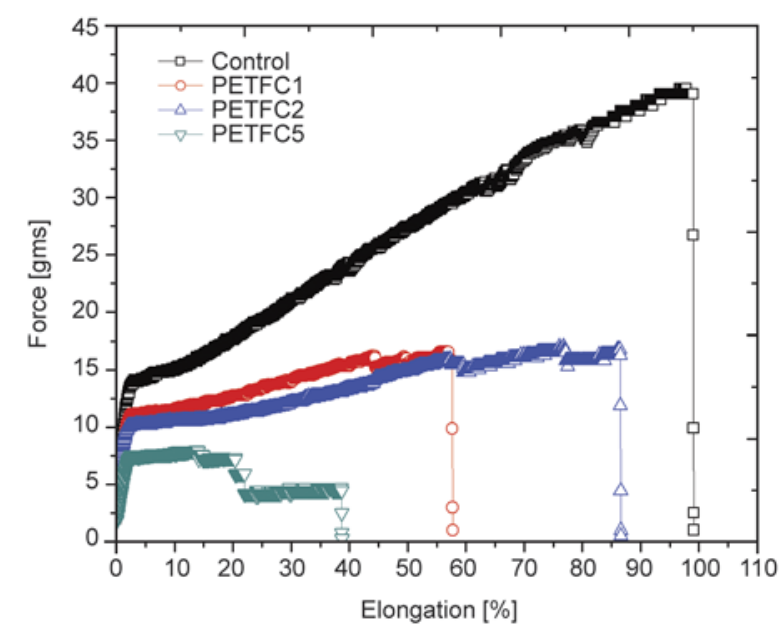

Figure 5. Single fiber tensile test results

ple with $1 \mathrm{wt} \%$ clay showed higher tenacity decrease in elongation indicates that the continuity in molecular network is lower compared to control PET fibers.

SEM micrographs of surface of PET fiber PETFC5 with $5 \mathrm{wt} \%$ clay sample are shown in Figure 6 . It is evident that the fiber diameter varies along the fiber surface. These surface imperfections are due to the protrusion of tactoids near fiber surface as shown in Figure $6 \mathrm{a}$ and $6 \mathrm{~b}$. Such imperfections contribute to deterioration in tensile properties as observed.

Failure mode was also different for the fibers with $5 \mathrm{wt} \%$ clay additives. Fibers showed brittle failure compared to ductile elongation and failure of control PET fibers. SEM and EDS analysis of $(n=10)$ tensile failed PET nanocomposite fiber failure spot
Table 3. Single fiber tensile properties of PET fibers

\begin{tabular}{|l|c|c|c|}
\hline \multicolumn{1}{|c|}{ Sample } & $\begin{array}{c}\text { Peak load } \\
\text { [gms] }\end{array}$ & $\begin{array}{c}\text { Peak elongation } \\
{[\%]}\end{array}$ & $\begin{array}{c}\text { Tenacity } \\
\text { [gms/den] }\end{array}$ \\
\hline Control PET & 35 & 78 & 3.6 \\
\hline PETFC1 & 16 & 42 & 1.7 \\
\hline PETFC2 & 16 & 57 & 1.6 \\
\hline PETFC5 & 10 & 14 & 1.0 \\
\hline
\end{tabular}

is shown in Figure 7a and 7b. Agglomerate particulate of $6 \mu$ was observed in the failure spot. These particulates were rich in nanoclay chemistry as revealed from EDS scans as shown in Figure 7c.

The structure and morphology of semi crystalline fiber is developed due to the stress-induced crystallization and molecular orientation in semi molten state immediately after extrusion of melt from orifice just before complete solidification. Semi-crystalline polymer fibers or products in molecular level consist of highly ordered crystalline segments, relatively unstable incomplete crystalline regions, transition segments between relatively unstable crystalline and amorphous regions, and unstable oriented amorphous fractions [31]. Mechanical properties like stiffness, strength and elongation exhibited by the fibers depend on the completeness and continuity between these four molecular segments. Transition in different molecular segments in a melt spun fiber subjected to tensile test is illustrated in Figures $8 \mathrm{a}$ to $8 \mathrm{~d}$.

In the melt spun fibers, additive agglomerates in fiber easily reach order of fiber magnitude [32]. Uniform dispersion of platelets is the key to achieve tensile

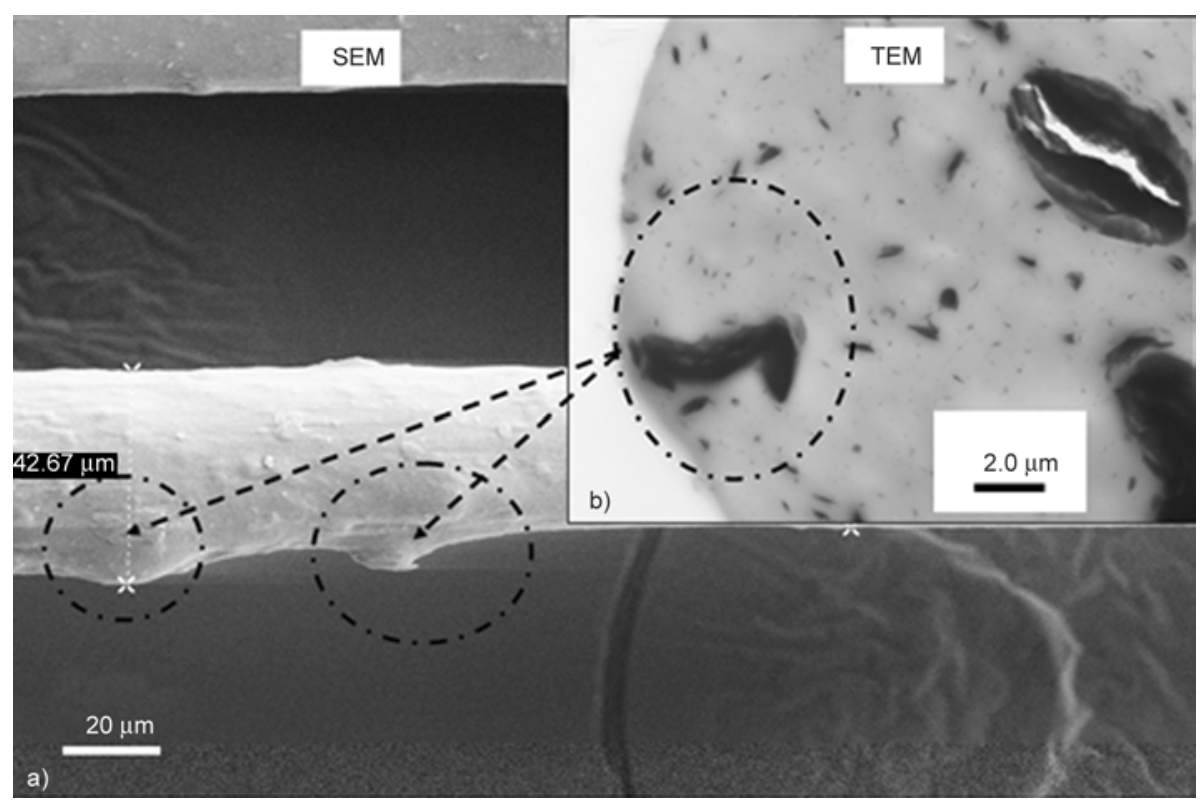

Figure 6. (a) SEM surface image of PETFC5, (b) TEM micrograph of PETFC5 with protrusion of agglomerate out of fiber surface 


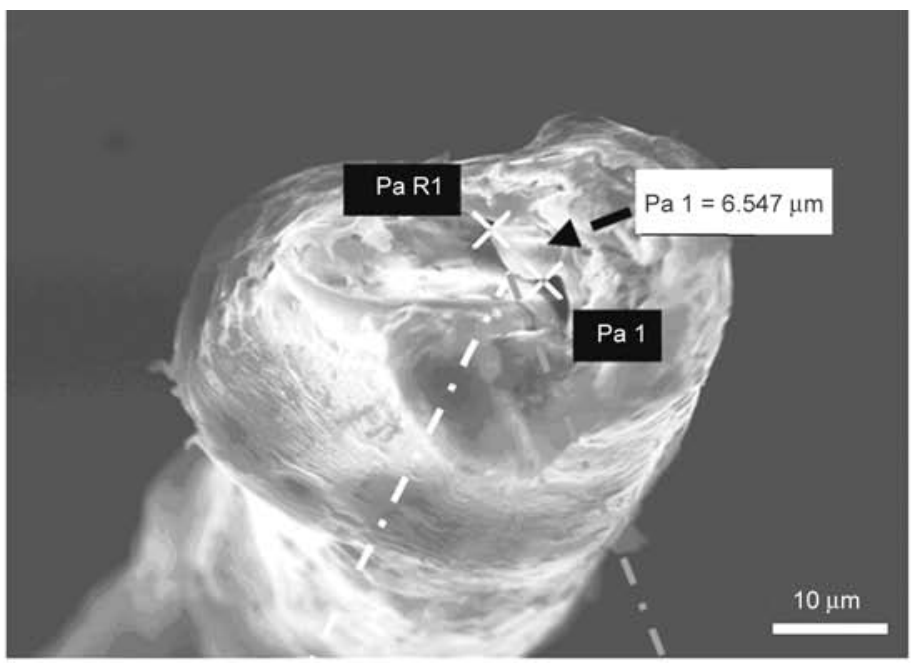

a)

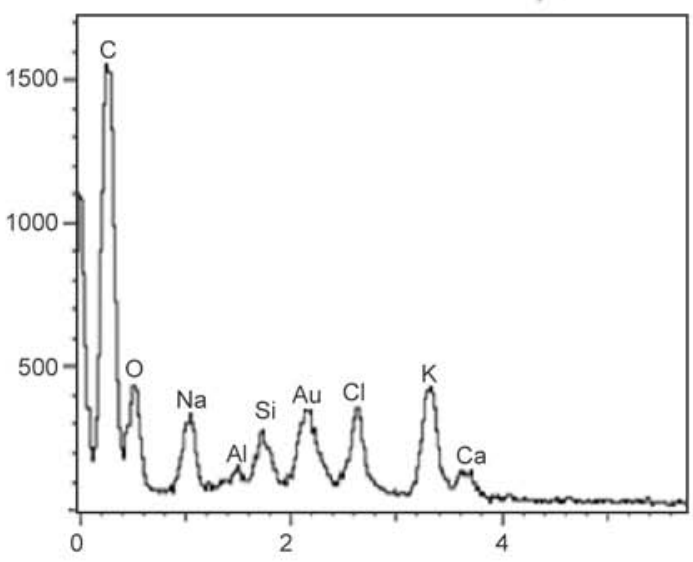

b)

Energy $[\mathrm{keV}]$

\begin{tabular}{|c|c|c|}
\hline Element type & Spectral type & Element \% \\
\hline $\mathrm{C}$ & $\mathrm{Ed}$ & 63.16 \\
\hline $\mathrm{O}$ & $\mathrm{Ed}$ & 14.97 \\
\hline $\mathrm{Na}$ & $\mathrm{Ed}$ & 0.35 \\
\hline $\mathrm{AL}$ & $\mathrm{Ed}$ & 4.56 \\
\hline $\mathrm{Si}$ & $\mathrm{Ed}$ & 15.93 \\
\hline $\mathrm{Cl}$ & $\mathrm{Ed}$ & 0.34 \\
\hline $\mathrm{K}$ & $\mathrm{Ed}$ & 0.64 \\
\hline $\mathrm{Ca}$ & $\mathrm{Ed}$ & 0.04 \\
\hline
\end{tabular}

c)

Figure 7. (a) SEM micrograph of PETFC5 failure spot with $5 \mathrm{wt} \%$ clay, (b) EDS scan of particulate in failure spot, (c) Elemental composition of particulate

property improvement. At lower weight percentage add on levels, as shown in Figure 8a-8e, if clay platelets are well dispersed in matrix, there will be a good load transfer between filler and matrix, which leads to increase in tensile strength. Also stiffness of fiber increases due to reinforcement in molecular network by high modulus nanoclay additives [13]. At higher weight percentage (Figure 8f), continuity in molecular network is lost because of generation of voids, which act as stress concentrates and lead to a brittle failure [3].

As revealed by SEM and TEM micrographs, fiber cross-section consists of significant tactoids and agglomerates even at lower weight $\%$ add on level. TEM micrograph of fiber with $5 \mathrm{wt} \%$ clay has larger agglomerates or tactoids as shown in Figure $3 \mathrm{~g}$. These tactoids have voids between their plates as shown in enlarged image in Figure $3 \mathrm{~h}$.
It is well known that there exist strong interactions between PET and the nano-sized platelets of MMT. The strong interactions between the PET molecule and clay platelets act as crosslink points and reinforce the molecular network. These physical cross linked points make the molecular network more complete and restrict the motion of molecules. Also, having additives may help cool the melt faster compared to control PET due to heat dissipation by nanoclay additives. Faster cooling and the strong interaction with the clay platelets will not allow the molten polymer to go through stress induced orientation and crystallization, which is required for the formation of strong melt spun fibers [14, 33].

In between the clay platelets, force of attraction is only the weak van der waals forces. So with the applied load, slippage of tactoids leads to voids formation. When subjected to drawing during tensile 

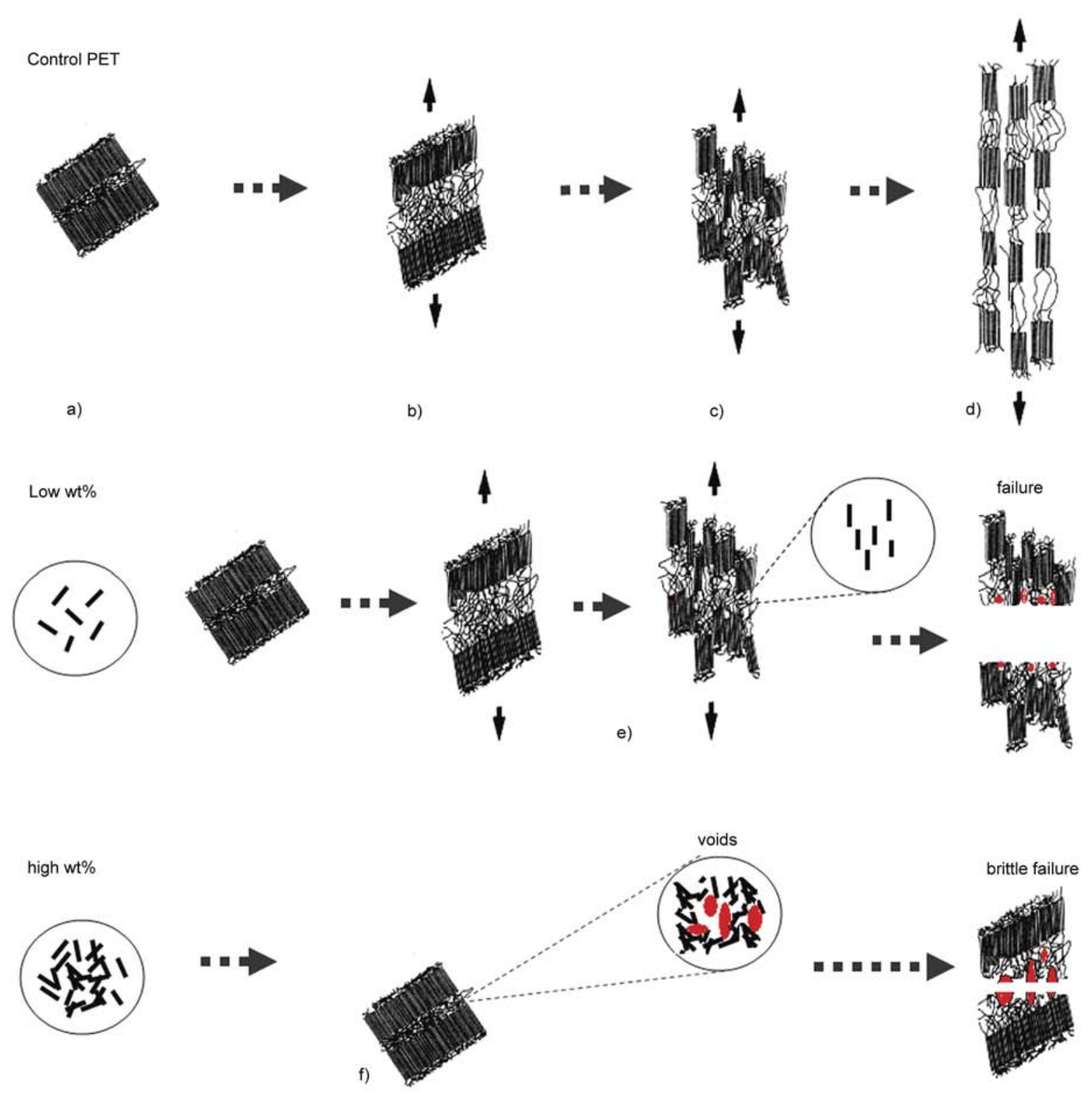

Figure 8. Schematic of morphology and transition in different molecular segments in a melt spun fiber nanocomposite subjected to tensile test, (a) stretching of amorphous segment, (b) shear yielding in crystalline, (c) void formation (d) re-crystallization with orientation (e) in case of fiber with lower weight percentage loading, there is reorientation of platelets in matrix, (f) in case of fiber with higher weight percentage reinforcement, agglomerates lead to amplification of voids and brittle failure

testing, these voids further get enlarged and act as stress concentrates. So, decrease in mechanical properties of fiber with higher wt $\%$ clay is due to debonding between platelets in tactoids and defect sites.

It is clear that, nanoclay additives do not always lead to improved mechanical properties in products. Observed behavior is a direct result of non-homogeneous dispersion, and agglomerates formed within the fiber. In melt spun fibers, lower weight percentage add-on levels, uniform dispersion, and process- ing optimization is necessary to obtain the property benefits from additives.

\section{Conclusions}

Structure and mechanical properties of nanoclay incorporated melt spun PET nanocomposite fibers were investigated. TEM micrographs revealed presence of tactoids in fibers with additives at all add on levels. Clay platelets showed difference in distribution due to 'wall effect' and extent of intercalation at near fiber surface and at fiber center due to higher 
shear rate near fiber surface. WAXD scans did not show any peak corresponding to clay platelets because the clay tactoids were delaminated and lacked ordered structure. Extent of dispersion of clay in the fiber matrix could not be detected from WAXD scans. Clay additives acted as nucleating agents and increased the overall crystallization kinetics. Even though nanoclay additives acted as nucleating agents, with accelerated crystallization kinetics, mechanical property benefits were not seen in fibers due to agglomeration. In the case of fibers with clay additives, strength and elongation dropped, and brittle failure mode was observed.

\section{References}

[1] Ke Y., Long C., Qi Z.: Crystallization, properties, and crystal and nanoscale morphology of PET-clay nanocomposites. Journal of Applied Polymer Science, 71, 1139-1146 (1999).

DOI: 10.1002/(SICI)1097-4628(19990214)71:7<1139 $:$ AID-APP12>3.0.CO;2-E

[2] Chang J-H., Mun M. K., Lee I. C.: Poly(ethylene terephthalate) nanocomposite fibers by in situ polymerization: The thermomechanical properties and morphology. Journal of Applied Polymer Science, 98, 2009-2016 (2005).

DOI: 10.1002/app.22382

[3] Xiao W., Yu H., Han K., Yu M.: Study on PET fiber modified by nanomaterials: Improvement of dimensional thermal stability of PET fiber by forming PET/MMT nanocomposites. Journal of Applied Polymer Science, 96, 2247-2252 (2005).

DOI: 10.1002/app.21703

[4] Bizarria M. T. M., de M. Giraldi A. L. F., de Carvalho C. M., Velasco J. I., d'Ávila M. A., Mei L. H. I.: Morphology and thermomechanical properties of recycled PET-organoclay nanocomposites. Journal of Applied Polymer Science, 104, 1839-1844 (2007).

DOI: $10.1002 / a p p .25836$

[5] Svoboda P., Zeng C., Wang H., Lee L. J., Tomasko D. L.: Morphology and mechanical properties of polypropylene/organoclay nanocomposites. Journal of Applied Polymer Science, 85, 1562-1570 (2002). DOI: $10.1002 / a p p .10789$

[6] Picard E., Vermogen A., Gérard J-F., Espuche E.: Barrier properties of nylon 6-montmorillonite nanocomposite membranes prepared by melt blending: Influence of the clay content and dispersion state: Consequences on modelling. Journal of Membrane Science, 292, 133-144 (2007).

DOI: $10.1016 /$ j.memsci.2007.01.030

[7] Bhat G., Hegde R. R., Kamath M. G., Deshpande B.: Nanoclay reinforced fibers and nonwovens. Journal of Engineered Fibers and Fabrics, 3, 22-34 (2008).
[8] Hegde R. R., Bhat G. S.: Nanoparticle effects on structure and properties of polypropylene meltblown webs. Journal of Applied Polymer Science, 115, 1062-1072 (2009). DOI: $10.1002 / a p p .31089$

[9] Hegde R. R., Bhat G. S.: Nanoparticle effects on the morphology and mechanical properties of polypropylene spunbond webs. Journal of Applied Polymer Science, 118, 3141-3155 (2010).

DOI: 10.1002/app.32304

[10] Kojima Y., Usuki A., Kawasumi M., Okada A., Fukushima Y., Kurauchi T., Kamigaito O.: Mechanical properties of nylon 6-clay hybrid. Journal of Materials Research, 85, 1185-1189 (1993).

DOI: $10.1557 /$ JMR.1993.1185

[11] Rangasamy L., Shim E., Pourdeyhimi B.: Structure and tensile properties of nanoclay-polypropylene fibers produced by melt spinning. Journal of Applied Polymer Science, 121, 410-419 (2011).

DOI: 10.1002/app.33619

[12] Yuan Q., Misra R. D. K.: Impact fracture behavior of clay-reinforced polypropylene nanocomposites. Polymer, 47, 4421-4433 (2006).

DOI: $10.1016 /$ j.polymer.2006.03.105

[13] Kawasumi M., Hasegawa N., Kato M., Usuki A., Okada A.: Preparation and mechanical properties of polypropylene-clay hybrids. Macromolecules, 30, 63336338 (1997).

DOI: $10.1021 / \mathrm{ma961786h}$

[14] Tjong S. C.: Structural and mechanical properties of polymer nanocomposites. Materials Science and Engineering R: Reports, 53, 73-197 (2006). DOI: $10.1016 /$ j.mser.2006.06.001

[15] Alexandre M., Dubois P.: Polymer-layered silicate nanocomposites: Preparation, properties and uses of a new class of materials. Materials Science and Engineering, 28, 1-63 (2000). DOI: $10.1016 / \mathrm{S} 0927-796 \mathrm{X}(00) 00012-7$

[16] Aranda P., Ruiz-Hitzky E.: Poly(ethylene oxide)-silicate intercalation materials. Chemistry of Materials, 4 , 1395-1403 (1992).

DOI: $10.1021 / \mathrm{cm} 00024 \mathrm{a} 048$

[17] Mayhan K. G., James W. J., Bosch W.: Poly(ethylene terephthalate). I. Study of crystallization kinetics. Journal of Applied Polymer Science, 9, 3605-3616 (1965).

DOI: 10.1002/app.1965.070091110

[18] Van Antwerpen F., Van Krevelen D. W.: Influence of crystallization temperature, molecular weight, and additives on the crystallization kinetics of poly(ethylene terephthalate). Journal of Polymer Science: Polymer Physics Edition, 10, 2423-2435 (1972).

DOI: 10.1002/pol.1972.180101211

[19] Kang X., He S., Zhu C., Wang L., Lü L., Guo J.: Studies on crystallization behaviors and crystal morphology of polyamide 66/clay nanocomposites. Journal of Applied Polymer Science, 95, 756-763 (2005). DOI: 10.1002/app.21257 
[20] Hegde R. R., Spruiell J. E., Bhat G. S.: Different crystallization mechanisms in polypropylene-nanoclay nanocomposite with different weight percentage of nanoclay additives. Journal of Materials Research, 27, 1360-1371 (2012).

DOI: $10.1557 /$ jmr.2012.37

[21] Jimenez G., Ogata N., Kawai H., Ogihara T.: Structure and thermal/mechanical properties of poly ( $\varepsilon$-caprolactone)-clay blend. Journal of Applied Polymer Science, 64, 2211-2220 (1997).

DOI: $10.1002 /($ SICI)1097-4628(19970613)64:11<2211 $\because$ AID-APP17>3.0.CO;2-6

[22] Lu X. F., Hay J. N.: Isothermal crystallization kinetics and melting behaviour of poly (ethylene terephthalate). Polymer, 42, 9423-9431 (2001). DOI: $10.1016 / \mathrm{S} 0032-3861(01) 00502-\mathrm{X}$

[23] Code of Federal Regulations, Food and Drug Administration: 21CFR 184.1155: Bentonite. (2012).

[24] ASTM D3822: Standard test method for tensile properties of single textile fibers (2007).

[25] Weng W., Chen G., Wu D.: Crystallization kinetics and melting behaviors of nylon 6/foliated graphite nanocomposites. Polymer, 44, 8119-8132 (2003). DOI: $10.1016 /$ j.polymer.2003.10.028

[26] Mucha M., Królikowski Z.: Application of DSC to study crystallization kinetics of polypropylene containing fillers. Journal of Thermal Analysis and Calorimetry, 74, 549-557 (2003). DOI: 10.1023/B:JTAN.0000005193.66789.ea
[27] Avrami M.: Kinetics of phase change. I General theory. Journal of Chemical Physics, 7, 1103-1112 (1939).

DOI: $10.1063 / 1.1750380$

[28] Sharples A.: Introduction to polymer crystallization. St Martin's Press, New York (1966).

[29] Schultz J. M.: Polymer crystallization. Oxford University Press, Washington (2001).

[30] Jiang X. L., Luo S. J., Sun K., Chen X. D.: Effect of nucleating agents on crystallization kinetics of PET. Express Polymer Letters, 1, 245-251 (2007). DOI: $10.3144 /$ expresspolymlett.2007.37

[31] Friedrich K., Karsch U. A.: Failure processes in particulate filled polypropylene. Fibre Science and Technology, 18, 37-52 (1981). DOI: 10.1016/0015-0568(83)90049-0

[32] Ergungor Z., Cakmak M., Batur C.: Effect of processing consitions on the development of morphology in clay nanoparticle filled nylon 6 fibers. Macromolecular Symposia, 185, 259-276 (2002).

DOI: 10.1002/1521-3900(200208)185:1<259::AIDMASY259>3.0.CO;2-0

[33] Hegde R. R., Bhat G. S., Deshpande B.: Morphology and properties of nylon 6 blown films reinforced with different weight percentage of nanoclay additives. International Journal of Polymer Science, 959035/1959035/14 (2012).

DOI: $10.1155 / 2012 / 959035$ 